
Copyright 81996 World Fcderation for Ultrasound in Medicinc \& Biology Printed in the USA. All rights reserved $0301-5629 / 96 \$ 15.00+.00$

\title{
THE RELATIONSHIP BETWEEN MYOCARDIAL INTEGRATED BACKSCATTER, PERFUSION PRESSURE AND WALL THICKNESS DURING ISOVOLUMIC CONTRACTION: AN ISOLATED PIG HEART STUDY
}

\author{
H. Rijsterborgh, ${ }^{\dagger}$ A. F. W. van Der SteEn, ${ }^{\dagger \neq}$ R. Krams, ${ }^{\dagger}$ F. MAstik, ${ }^{\dagger}$ \\ C. T. LANCÉE, ${ }^{\dagger}$ P. D. Verdouw ${ }^{\dagger}$ J. R. T. C. RoElandT ${ }^{\dagger}$ and N. BOM ${ }^{\dagger \neq}$ \\ 'Department of Cardiology, Thorax Centre, Erasmus University Rotterdam, The Netherlands; and \\ Interuniversity Cardiology Institute of The Netherlands, Rotterdam, The Netherlands
}

(Received 10 May 1995; in final form 4 July 1995)

\begin{abstract}
To investigate the independent effect of myocardial wall thickness and myocardial perfusion pressure on integrated backscatter, experiments were designed in which integrated backscatter of normally perfused myocardial tissue was measured while changes in wall thickness during the cardiac cycle were reduced to a minimum. In nine blood-perfused isolated pig hearts, perfusion pressure was uncoupled from left ventricular pressure generation (Langendorff method) and isovolumic contraction and relaxation were realized by inserting a noncompressible water-filled balloon into the left ventricle. In a first experiment, at constant perfusion pressure $(85 \mathrm{mmHg})$, the integrated backscatter (3-7 $\mathrm{MHz})$, the myocardial wall thickness and the left ventricular pressure were determined simultaneously at various balloon volumes (5$25 \mathrm{~mL}$ ). A quasistatic increase of balloon volume by $50 \%$ resulted in an average decrease of wall thickness of 6.5\% $(p<0.01)$ and a mean increase in the integrated backscatter level of $1.1 \mathrm{~dB}(p<0.01)$. Integrated backscatter levels increased statistically significant by $0.14 \pm 0.014 \mathrm{~dB}$ per percent decrease of wall thickness. Measurements of percentage end-systolic myocardial wall thickening ranged from $-10 \%$ to $+10 \%$, mean $0.15 \pm 4.5 \%$ (NS from zero); whereas cyclic variation of integrated backscatter ranged from -3.9 to +3.9 dB, mean $0.19 \pm 1.5 \mathrm{~dB}$ (NS from zero). In a second experiment, at a constant midrange balloon volume, the same parameters were determined simultaneously at various perfusion pressures $(20-120 \mathrm{mmHg})$. An increase in perfusion pressure by $50 \%$ resulted in a small but statistically significant increase of $1.5 \%$ in myocardial wall thickness, which could be explained by an increase of intravascular volume. The integrated backscatter levels did not change statistically significantly. Measurements of percentage end-systolic myocardial wall thickening ranged from -8.9 to $+7.8 \%$, mean $0.13 \pm 4.0 \%$ (NS from zero); whereas cyclic variation of integrated backscatter ranged from -1.8 to $+4.2 \mathrm{~dB}$, mean $0.37 \pm 1.3 \mathrm{~dB}$ (NS from zero). The magnitude of cyclic variation of integrated backscatter of myocardial tissue in a contractile state is reduced if myocardial muscle is prevented from normal thickening. In addition, changes in intravascular volume during the cardiac cycle have a negligible influence on the absolute backscatter level or its cyclic variation. We conclude, if only wall thickness and perfusion pressure are involved, that integrated backscatter is mainly determined by myocardial wall thickness.
\end{abstract}

Key Words: Ultrasound, Myocardium, Contractility, Integrated backscatter, Wall thickening, Perfusion, Isolated heart.

\section{INTRODUCTION}

The cyclic variation of ultrasound myocardial integrated backscatter during the cardiac cycle is widely regarded as a parameter to assess regional myocardial contractile performance (Barzilai et al. 1984; Glueck

Address for correspondence: Ton van der Steen Ph.D., Laboratory of Experimental Echocardiography, Thorax Centre, Room Ee2302, P.O. Box 1738, 3000 DR Rotterdam, The Netherlands. Email ASTEEN@TCH.FGG.EUR.NL et al. 1985; Mottley et al. 1984; Sagar et al. 1987, 1988; Wear et al. 1986, 1989; Wickline et al. 1985a,b). This cyclic variation of normal myocardial tissue as well as its disappearance during acute myocardial ischemia (Barzilai et al. 1984; Maderas et al. 1983; Miller et al. 1983; Mimbs et al. 1981) can be explained by an empirical relation between myocardial integrated backscatter and myocardial wall thickness. This relationship appears to be maintained during acute ischemic periods (Rijsterborgh et al. 1991). 
However, it should be realized that the relationship between myocardial wall thickness and integrated backscatter level is not perfect. Some hysteresis can be observed in plots of integrated backscatter versus wall thickness (Rijsterborgh et al. 1991) and, in addition, a fairly large intersubject variation of the absolute integrated backscatter level has been reported in pig myocardium ( Rijsterborgh et al. 1991; van der Steen et al. 1991). These observations suggest that parameters, other than myocardial wall thickness, modulate the level of integrated backscatter from cardiac tissue. Under in vivo circumstances it is difficult to separate the contribution of wall thickness to the integrated backscatter levels from possible other mechanisms.

\section{Purpose of the study}

The first aim of this study was to devise an in vitro experiment to analyze the effect of myocardial tension on integratcd backscatter levels in normally perfused myocardium. The hypotheses to be tested are:

Hypothesis I. The integrated backscatter level will change with myocardial tension under conditions of constant wall thickness and constant perfusion pressure.

Rationale - there may be a change in acoustic backscatter properties of the myofibers as their tension varies over the cardiac cycle. Under normal circumstances, there is both a cyclic variation of active tension and wall thickening and both factors might result in a cyclic variation of integrated backscatter. During acute ischemia, there is locally no myocardial activity, no active tension generation and both the wall thickening and the cyclic variation of the backscatter disappears.

The second aim of this study was to use the same experimental setup to analyze the effect of myocardial perfusion on integrated backscatter levels. A second hypothesis was:

Hypothesis II. The integrated backscatter level will change with intramyocardial vessel volume under conditions of constant wall thickness.

Rationale - the myocardium is a complex mixture of muscle tissue and extracellular structures, including the myocardial vessels. The intramyocardial vascular volume changes by approximately $30 \%$ during the cardiac cycle (Spaan 1991); therefore, the intramyocardial vessels must change in diameter, which might influence the level of integrated backscatter and its cyclic variation. In normally perfused myocardial tissue a cyclic variation of the vascular volume coincides with a cyclic variation in wall thickness. Both might result in a cyclic variation of integrated backscatter. During acute ischemia, there is no perfusion and both the wall thickening and the cyclic variation of the backscatter disappear. However, after a short period of ischemia in dog myocardium, when the myocardium is stunned but viable, cyclic variation of integrated backscatter is restored despite a reduced wall thickening ( $\mathrm{Mi}$ lunski et al. 1989a,b). A possible explanation is, because perfusion flow is normal to high, that a cyclic variation of the diameters of the intramyocardial vessels causes the cyclic variation of integrated backscatter.

\section{Layout of the experiment}

In blood-perfused isolated pig hearts (Langendorff method), isovolumic contractions were realized by inserting a noncompressible water-filled balloon into the left ventricle. This setup enabled us to control coronary perfusion pressure independently of left ventricular pressure (Krams et al. 1994; Stubbs and Widdas 1959). The presence of the balloon in the left ventricle caused a scvere reduction of regional wall thickening, despite a constant contractile state of the myocardium. This method offers the possibility to explore the cyclic variation of integrated backscatter produced by normal myocardial tissue, having a severely reduced wall thickening, at a constant perfusion pressure. By adjusting the balloon volume, different average myocardial wall thicknesses could be realized to explore the relationship between wall thickness and integrated backscatter levels in a quasistatic manner. In addition, we changed perfusion pressure at constant left ventricular balloon volume and investigated the relationship between myocardial integrated backscatter levels and the coronary perfusion pressure and coronary flow.

\section{METHODS}

\section{Animal preparation}

The experiments were performed on hearts of young Yorkshire pigs according to the guiding principles for the care and use of animals outlined by the American Physiological Society and approved by the Committee on Animal Experiments of the Erasmus University. Healthy hearts (weight range 78-147 g) were obtained from nine overnight-fasted crossbred Landrace Yorkshire pigs (14$23 \mathrm{~kg}$ ), which had been sedated with $4 \mathrm{mg} / \mathrm{kg}$ azaperone (Stresnil, Jansen Pharmaceutica, Beerse, Belgium), anaesthetized with $5 \mathrm{mg} / \mathrm{kg}$ metomidate intravenously (Hypnodil, Jansen Pharmaceutica), intubated and connected to a ventilator for intermittent positive pressure ventilation with a mixture of $\mathrm{O}_{2}$ and $\mathrm{N}_{2} \mathrm{O}(1: 2 \mathrm{v} / \mathrm{v})$. Respiratory rate and tidal volume were set (ABL-3, Radiometer, Copenhagen, Denmark) to keep arterial blood gases within normal limits. Catheters placed in the superior vena cava were used for administration of $100 \mathrm{mg} / \mathrm{kg}$ $\alpha$-chloralose (Merck, Darmstadt, Germany), followed by an intravenous infusion of 3-4 $\mathrm{mg} / \mathrm{kg}$ per hour sodium 
pentobarbitone (Sanofi, Paris, France) for anaesthesia. Aortic pressure was obtained with a 7F microtipped catheter (Sensodyn, Braun Medical, Uden, The Netherlands ).

After exposure of the heart, via a midsternal thoracotomy, the blood was exchanged with a dextran solution (Isodex, NPBI) until mean arterial pressure had decreased to $50 \mathrm{mmHg}$, i.e., the lower range of the coronary autoregulation curve, to avoid myocardial ischemia (Spaan 1991).

Depending on the weight of the animals, $0.5-1.0 \mathrm{~L}$ of whole blood could be collected in standard blood bags (Compoflex, NPBI, Emmer Compascuum, The Netherlands). The hearts were then fibrillated by applying a low DC current to the free wall, with the aorta clamped and incised distally from the clamp to prevent air flowing into the coronary vascular tree. The hearts were then isolated and arrested in $500 \mathrm{~mL} \mathrm{St}$. Thomas cardioplegic solution at $4^{\circ} \mathrm{C}$. All further surgical procedures were done in this solution and at this temperature.

\section{Isolated heart preparation}

Before isolation of the hearts, the system was primed with an albumin solution (containing $10 \mathrm{~g} / \mathrm{L}$ albumin, bovine fraction V, Sigma, St. Louis, MO, USA) for $1 \mathrm{~h}$. This approach prevented fibrinogen deposition and platelet aggregation for up to $2 \mathrm{~h}$ as measured by the platelet count and (relative) platelet distribution. The system was then filled with haemaccel (Behringwerke, Marburg, Germany) to which 10 mmol/L glucose (Merck) was added. During the isolation and preparation of the heart, the system was filled with the collected autologous blood. Preparation of the heart consisted of cannulation of the aorta, the pulmonary artery and the apex. The aorta was cannulated with a metal cannula that could easily be connected to a windkessel. The pulmonary artery was cannulated to collect coronary venous outflow and to prevent exposure to air.

A tight coupling between the balloon and the endocardial wall was assured by cannulating the apex with a stiff cannula (outer diameter $1 \mathrm{~mm}$, length 10 $\mathrm{cm}$ ) to collect Thebesian flow and creating a subatmospheric pressure outside the balloon (Goto et al. 1988a). The left atrium was incised and the mitral valve and chordae tendineae were carefully dissected. A purse string was placed around the left atrium and a latex balloon (unstressed volume $80 \mathrm{~mL}$ ) was inserted into the left ventricle via the mitral valve, to generate isovolumic left ventricular pressures uncoupled from coronary perfusion pressure. The balloon was mounted on a sturdy transparent frame. The latter allowed the detection of ( small) air bubbles. An adjustable rim was connected to the frame just above the connection with the balloon to adjust for variable mi- tral openings to prevent the ejection of the balloon out of the ventricle. A glass cannula was inserted from the top of the frame into the balloon to measure intraventricular pressure. Two pacing wires were sewed onto the conus arteriosus and connected to a Grass stimulator to control and set the heart rate at 100 beats per minute. Coronary perfusion pressure (measured approximately $1 \mathrm{~cm}$ above the origin of the coronary bed) and left ventricular pressure (inside the balloon) were measured using P23 Statham pressure transducers (Haton Ress, Puerto Rico).

\section{Isolated heart perfusion}

The perfusion system consisted of a bubble oxygenator (Polystan, Copenhagen, Denmark), a doublelumen reservoir, an occlusive pump (Verder, Vleuten, The Netherlands) and a double-lumen windkessel to damp pressure oscillations. The pump was externally controlled by the perfusion pressure with a feedback system developed at the university workshop. The windkessel and reservoir both served as heat exchangers ( $37^{\circ} \mathrm{C}$ ). A blood filter ( $40 \mu \mathrm{m}$, Pall Biomedical Inc., Portsmouth, UK) was inserted before the windkessel, to prevent thrombocyte aggregates reaching the heart.

\section{Experimental protocol}

Isovolumic contraction at various thicknesses and constant perfusion pressure. The perfusion pressure was set at approximately $85 \mathrm{mmHg}$ and was kept constant during the remainder of the protocol. After a stabilization period of approximately $30 \mathrm{~min}$ the volume of the balloon was varied between 5 and $40 \mathrm{~mL}$ in a random order using eight different volumes. This wide range in volume was chosen to cover a range of peak systolic left ventricular pressures between 20 and $100 \mathrm{mmHg}$. At each volume, the radio-frequency ultrasound backscatter signals and left ventricular pressure curves of five cardiac cycles were recorded.

Isovolumic contraction at various perfusion pressures and constant volume. After this procedure, the balloon volume was set at a midrange volume and the perfusion pressure was varied between 20 and 120 $\mathrm{mmHg}$, using six different values. At each pressure, the radio-frequency ultrasound backscatter signals and left ventricular pressure curves of five cardiac cycles were recorded. The lower pressures were applied for only a short period of time to prevent the heart from becoming ischemic.

Contractile performance. Contractile performance of the isolated heart was assessed by estimating the loadindependent slope $\left(E_{\max }\right)$ and the intercept $\left(V_{0}\right)$ of the relationship between left ventricular volume and the max- 
imum systolic left ventricular pressure using simple linear regression analysis (Suga et al. 1973).

In each part of the protocol, each run started and ended with the same balloon volume and perfusion pressure. If the end-systolic left ventricular pressures from the first and last measurements did not differ more than $10 \%$, the preparation was considered to have remained stable during the protocol.

\section{Data acquisition}

A computer-based radio-frequency data acquisition system was applied to obtain simultaneous measurements of myocardial integrated backscatter, myocardial wall thickness and left ventricular pressure (Lancée et al. 1988; Rijsterborgh et al. 1990, 1991 ).

Radio-frequency ultrasound signals were acquired at a rate of 50 times the pig's heart rate, using an unfocused 4.7-MHz ultrasound transducer (Krautkramer-Branson, Lewistown, PA, USA) sutured directly on the vascular free surface in the distribution area of the left anterior descending coronary artcry, while ensuring perpendicular insonification of the myocardial fibres. This sctup ensures a stable location in the myocardium during the experiments; however, it also prevents spatial averaging. Ultrasound waves were generated and amplified by an transmitter/receiver system developed in-house. (Rijsterborgh et al. 1990). The ultrasound backscatter signals were sampled with a resolution of eight bits and a sample frequency of $25 \mathrm{MHz}$ by a computer-controlled digital oscilloscope (LeCroy 9400, Geneva, Switzerland). The length of each recorded trace was $19.9 \mu$ s corresponding with a penetration depth of $15.7 \mathrm{~mm}$. A simultaneous left ventricular pressure curve was digitized and stored.

\section{Data processing}

Signal processing was performed off-line. A split cosine bell window ( $p=0.1$; Bloomfield 1976) with a time interval of $5 \mu$ s was used to exclude the specular reflections from the epicardial and endocardial walls. Power spectra were obtained by a Fourier transform and integrated backscatter was calculated by integrating the spectra over the useful frequency bandwidth from 3.2 to $7.2 \mathrm{MHz}$.

To measure the myocardial wall thickness, the acquired ultrasound signals of complete cardiac cycles were displayed in brightness mode on a video-monitor using a 30-dB logarithmic signal compression. The endocardial wall was traced manually. Only the measurements of cardiac cycles containing clearly visualized borders were selected for further analysis.

The temporal measurements of backscatter, myocardial wall thickness and left ventricular pressure of the five consecutive cardiac cycles of every sequence were resampled in time on the basis of the pressure curve. The time scales of the cardiac cycles were normalized to a linear scale expressed as a percentage of the cardiac cycle ranging from $0 \%$ (begin systole) to $100 \%$ (end diastole) with $2 \%$ increments (total of 50 points per cardiac cycle). Mean values and standard deviations of the measurements were calculated for every $2 \%$ time increment of the cardiac cycle

\section{Data evaluation}

The measurements were evaluated in two ways. First, the cyclic variation of the integrated backscatter was explored in relation to the percentage myocardial wall thickening. Second, the relationship between integrated backscatter and wall thickness was assessed as a function of balloon volume and perfusion pressure.

Cyclic variation of the integrated power was defined as the difference between end-systolic and enddiastolic integrated backscatter. End-systole was defined as the time interval from $30 \%$ to $46 \%$ of the cardiac cycle and end-diastole as the time interval from $80 \%$ to $96 \%$ (Rijsterhorgh et al. 1990). End-systolic and end-diastolic levels of integrated power were calculated by averaging over the above-mentioned intervals. Wall thickening was calculated as the ratio of the difference between systolic thickness and diastolic thickness and end-diastolic wall thickness.

To investigate the measurements related to the changes of balloon volume or of perfusion pressure, the measurements of integrated backscatter and wall thickness were averaged over the cardiac cycle. Because the hearts studied showed a large variation in size (weight range $78-147 \mathrm{~g}$ ), the measurements were transformed into relative measurements, related to the mean value of the measurements obtained in every heart separately during the volume variations and the perfusion variations.

\section{Statistical analysis}

Mean values of the cyclic variation of the integrated backscatter and percentage end-systolic myocardial wall thickening were calculated from the measurements obtained during constant perfusion pressure and during constant balloon volume. These values were tested versus zero to confirm the hypothesis that there is no cyclic variation of integrated backscatter and no wall thickening during isovolumic contraction. Simple linear regression analysis was performed on the paired measurements of cyclic variation and percentage end-systolic wall thickening.

Concerning the quasistatic evaluation of the parameters, simple linear regression analysis was performed between the changes of both integrated back- 
scatter and wall thickness, respectively, versus the changes of both balloon volume and perfusion pressure, respectively. In addition, the relationship betwcen the changes of integrated backscatter and the changes of wall thickness was explored by simple lincar regression analysis.

To determine the contractility of these isolated pig hearts, the $E_{\max }$ value was obtained from the slope of the linear relation between peak systolic pressure and left ventricular volume.

Results are reported as mean values \pm standard deviations. For all statistical tests, a level of $p<0.01$ was considered statistically significant.

\section{RESULTS}

Heart weights ranged from 78.5 to $146.8 \mathrm{~g}$ ( $108 \pm$ $23 \mathrm{~g}$ ). The average slope of the peak-systolic pressure/ volume relation $\left(E_{\max }\right)$, normalized to $100 \mathrm{~g}$ heart weight, was $3.89 \pm 1.97 \mathrm{mmHg} / \mathrm{mL}$ per $100 \mathrm{~g}$. Specimen-specific data on the contractility index $\left(E_{\max }\right)$, percentage end-systolic myocardial wall thickening and cyclic variation of the integrated backscatter are given in Table 1.

Cyclic variation of integrated backscatter and endsystolic wall thickening during isovolumic contraction at constant perfusion pressure

In the nine pig hearts, measurements were made at 70 different balloon volumes at a constant perfusion pressure of approximately $85 \mathrm{mmHg}$. In one episode, the myocardial wall thickness could not be measured due to insufficient visualization of the endocardial border of the myocardium.
Figure la shows an cxample of the changes in integrated backscatter, myocardial wall thickness and left ventricular pressure during the cardiac cyclc. For comparison, earlier measurements obtained in an openchested pig with normal systolic thickening are depicted in Fig. 1b.

Measurements of percentage end-systolic myocardial wall thickening, obtained during individual episodes, ranged from -10 to $+10 \%(0.15 \pm 4.5 \%$, not significant from zero), whereas cyclic variation of integrated backscatter ranged from -3.9 to $+3.9 \mathrm{~dB}(0.19$ $\pm 1.5 \mathrm{~dB}$, not significant from zero). The results of the linear regression analysis between the paired measurements of end-systolic wall thickening and integrated backscatter did not reach the predetermined level of significance.

Cyclic variation of integrated backscatter and endsystolic wall thickening during isovolumic contraction at constant volume and variable perfusion pressures

At a constant, midrange, balloon volume, measurements were made at 53 different perfusion pressures. In three episodes in the same heart, the myocardial wall thickness could not be measured due to insufficient visualization of the endocardial border of the myocardium. Measurements of percentage end-systolic myocardial wall thickening, obtained during individual episodes, ranged from -8.9 to $7.8 \%(-0.13 \pm 4.0 \%$, not significant from zero), whereas cyclic variation of integrated backscatter ranged from -1.8 to $+4.2 \mathrm{~dB},(0.37 \pm 1.3$ $\mathrm{dB}$, not significant from zero). No statistically significant relationship was found between the paired measurements of end-systolic wall thickening and integrated backscatter.

Tahle 1. Mean values \pm standard deviations of the contractility index $\left(E_{\max }\right)$, the end-systolic myocardial wall thickening and cyclic variation of integrated backscatter.

\begin{tabular}{|c|c|c|c|c|c|c|c|c|}
\hline \multirow[b]{2}{*}{$\begin{array}{l}\text { Heart } \\
\text { no. }\end{array}$} & \multirow[b]{2}{*}{$\begin{array}{l}\text { Weight } \\
(\mathrm{g})\end{array}$} & \multicolumn{4}{|c|}{ Balloon volume variations at constant perfusion pressure } & \multicolumn{3}{|c|}{$\begin{array}{l}\text { Perfusion pressure variations at constant } \\
\text { balloon volume }\end{array}$} \\
\hline & & $\begin{array}{l}\text { Number of } \\
\text { episodes } \\
\text { measured }\end{array}$ & $\begin{array}{c}E_{\max } \\
(\mathrm{mmHg} / \mathrm{mL} \text { per } 100 \mathrm{~g}) \\
\end{array}$ & $\begin{array}{c}\text { End-systolic } \\
\text { thickening } \\
(\%)\end{array}$ & $\begin{array}{l}\text { Cyclic } \\
\text { variation } \\
(\mathrm{dB})\end{array}$ & $\begin{array}{l}\text { Number of } \\
\text { episodes } \\
\text { measured }\end{array}$ & $\begin{array}{c}\text { End-systolic } \\
\text { thickening } \\
(\%)\end{array}$ & $\begin{array}{c}\text { Cyclic } \\
\text { variation } \\
(\mathrm{dB})\end{array}$ \\
\hline 1 & 83.0 & 6 & $2.4 \pm 0.7$ & $3.8 \pm 2.7$ & $1.0 \pm 2.0$ & 7 & $-0.3 \pm 1.7$ & $1.2 \pm 1.0$ \\
\hline 2 & 146.8 & 8 & $3.1 \pm 0.4$ & $1.1+1.1$ & $0.1 \pm 1.3$ & 4 & $1.6 \pm 1.3$ & $-1.5 \pm 0.4$ \\
\hline 3 & 105.7 & 6 & $6.7 \pm 1.0$ & $-4.9 \pm 3.4$ & $0.7 \pm 0.5$ & 8 & $-3.5 \pm 2.7$ & $0.2 \pm 0.4$ \\
\hline 4 & 106.2 & 8 & $6.3 \pm 1.0$ & $6.6 \pm 1.9$ & $1.2 \pm 1.1$ & 7 & $6.2 \pm 1.2$ & $0.9 \pm 0.7$ \\
\hline 5 & 134.5 & 10 & $2.2 \pm 0.7$ & $3.1 \pm 1.8$ & $-1.1 \pm 0.9$ & 5 & $3.9 \pm 1.0$ & $-0.3 \pm 0.6$ \\
\hline 6 & 87.5 & 5 & $2.2 \pm 0.2$ & $-0.5 \pm 2.2$ & $1.9 \pm 1.1$ & 4 & $0.1^{\ddagger}$ & $3.1 \pm 1.0$ \\
\hline 7 & 78.5 & 7 & $3.5 \pm 1.1$ & $-0.1 \pm 2.5$ & $0.8 \pm 1.4$ & 6 & $-2.3 \pm 0.7$ & $0.3 \pm 1.2$ \\
\hline 8 & 122.2 & 11 & $2.3 \pm 0.5$ & $-1.0 \pm 1.8^{\dagger}$ & $-0.8 \pm 1.5$ & 7 & $-0.6 \pm 1.9$ & $-0.1 \pm 0.6$ \\
\hline 9 & 105.5 & 9 & $6.4 \pm 1.0$ & $-6.9 \pm 1.9$ & $-0.4 \pm 1.5$ & 5 & $-5.6 \pm 3.1$ & $-0.8 \pm 0.5$ \\
\hline Mean & $108 \pm 23$ & & $3.89 \pm 2.0$ & $0.15 \pm 4.5$ & $0.19 \pm 1.5$ & & $-0.13 \pm 4.0$ & $0.37 \pm 1.3$ \\
\hline
\end{tabular}

${ }^{+}$Myocardial wall thickness of ten episodes was measured.

${ }^{\ddagger}$ Myocardial wall thickness of one episode was measured. 

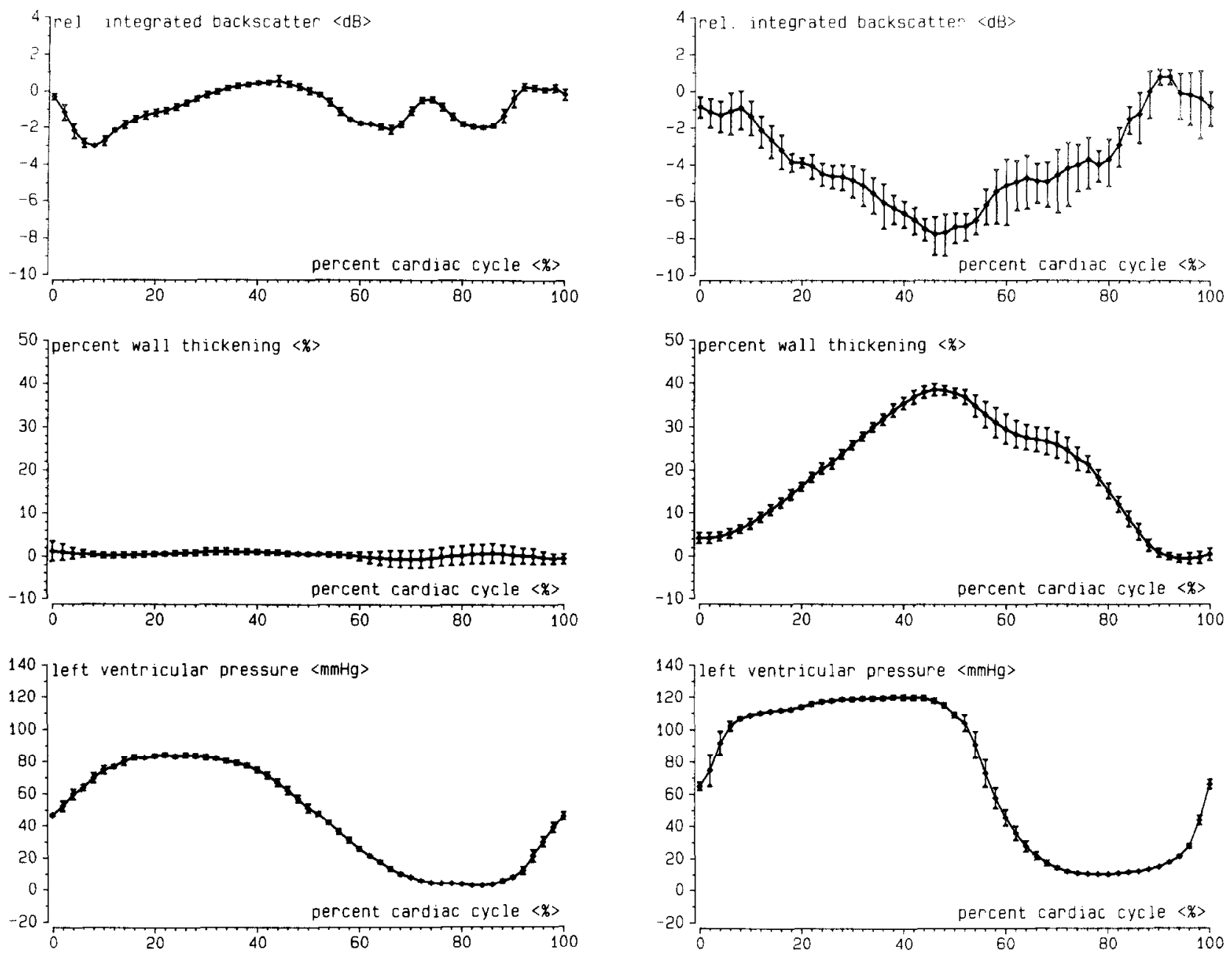

(a)

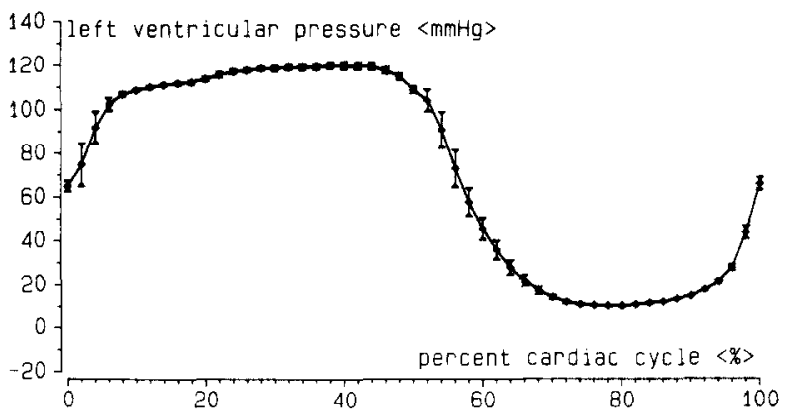

(b)

Fig. 1. (a) A result of the present study. The time-dependent measurements of relative integrated backscatter (top), percentage myocardial wall thickening (middle) and left ventricular pressure (bottom). The measurements of integrated backscatter and wall thickening are related to the end-diastolic values. Shown are the mean values (diamonds) and standard deviations (bars) of five cardiac cycles at a balloon volume of $12 \mathrm{~mL}$ and a perfusion pressure of $76 \mathrm{mmHg}$. (b) A result of a previous study in an open-chest pig heart. The time-dependent measurements of relative integrated backscatter (top), percentage myocardial wall thickening (middle) and left ventricular pressure (bottom). The measurements of integrated backscatter and wall thickening are related to the end-diastolic values. Shown are the mean values (diamonds) and standard deviations (bars) of 10 cardiac cycles of the heart during normal contractile performance (adapted from Rijsterborgh et al. 1990).

The quasistatic assessment of the relationship between integrated backscatter and wall thickness at constant perfusion pressure.

At constant perfusion pressure, myocardial wall thickness decreased significantly with the increase of the balloon volume (slope of regression line $0.13 \pm 0.013$ ), whereas the integrated backscatter increased significantly by $0.021 \pm 0.0029 \mathrm{~dB}$ per percent balloon volume increase. The scatter plots of these measurements are depicted in Fig. 2. Simple linear regression between the paired measurements of the change of integrated backscatter and the change of myocardial wall thickness re- sulted in a significant slope of $-0.14 \pm 0.014 \mathrm{~dB}$ per percent (Fig. 3).

The quasistatic assessment of the relationship between integrated backscatter and wall thickness at constant volume

At constant balloon volume, linear regression showed a small, but statistically significant (slope $0.030 \pm 0.0083 \% / \%$ ) increase of myocardial wall thickness per percent increase of perfusion pressure. No statistically significant relationships were found between the change of integrated backscatter (slope 

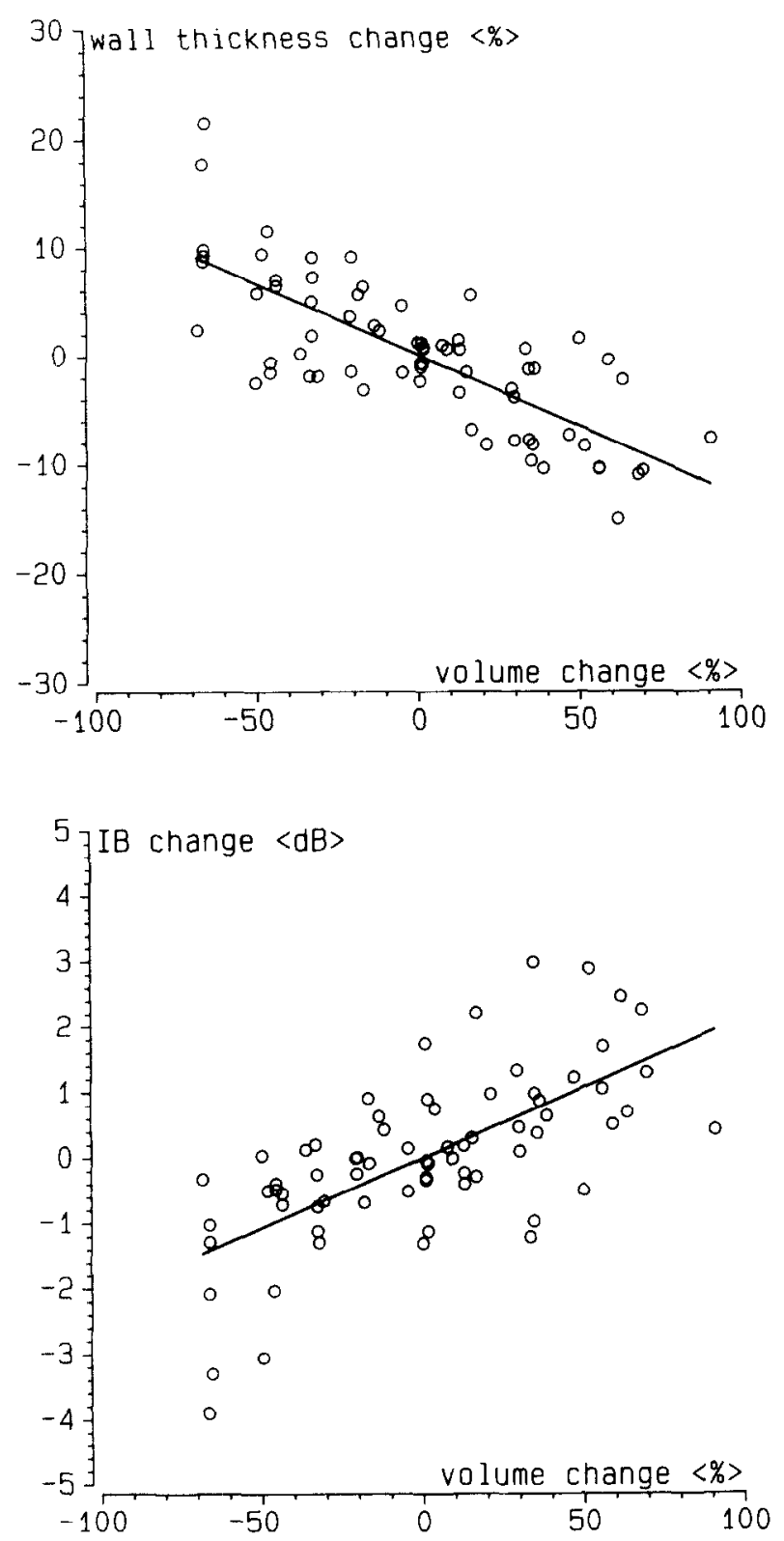

Fig. 2. The relationship of the changes in wall thickness (top) and integrated backscatter (IB, bottom) versus the changes of the balloon volume obtained during the experiments at constant perfusion pressure.

$-0.0026 \pm 0.0020 \mathrm{~dB} / \%$ ) with the change of perfusion pressure (Fig. 4) and the paired measurements of the changes of integrated backscatter and myocardial wall thickness (slope $-0.036 \pm 0.33 \mathrm{~dB}$ per percent).

\section{DISCUSSION}

The Langendorff-perfused heart allowed the control of perfusion pressure and left ventricular volumes independently and therefore enabled the study of the quasistatic wall thickness-integrated backscatter rela-

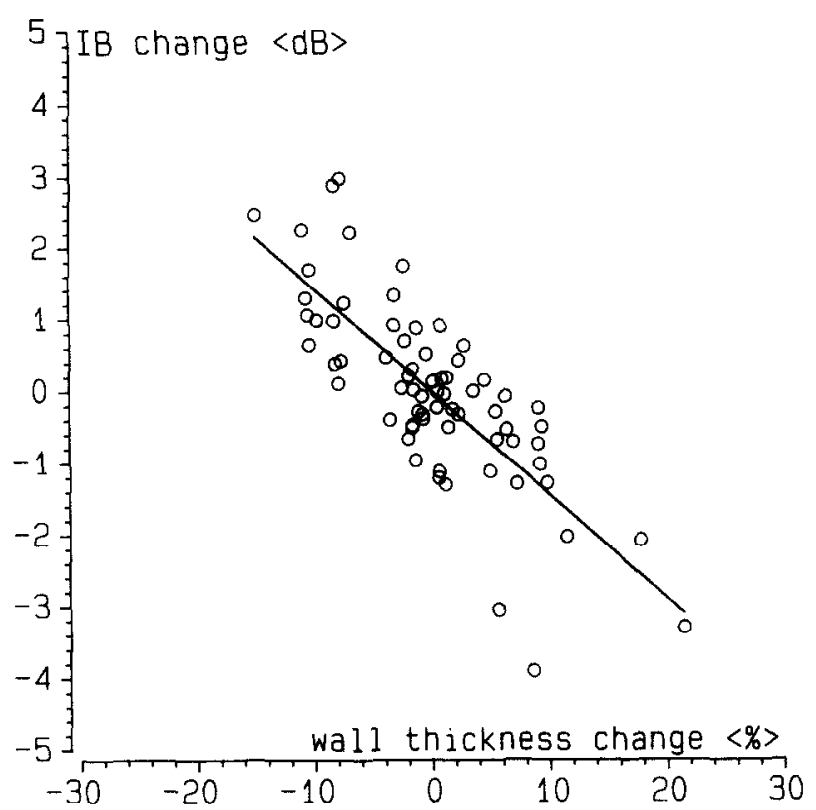

Fig. 3. The relationship between the change of integrated backscatter (IB) measurcments and the change of wall thickness as a result of the change in balloon volume at constant perfusion pressure.

tionship within a range normally encountered in in vivo conditions. Furthermore, it enabled us to study selectively the independent effect of changes in perfusion pressure on the levels of integrated backscatter at a constant left ventricular volume.

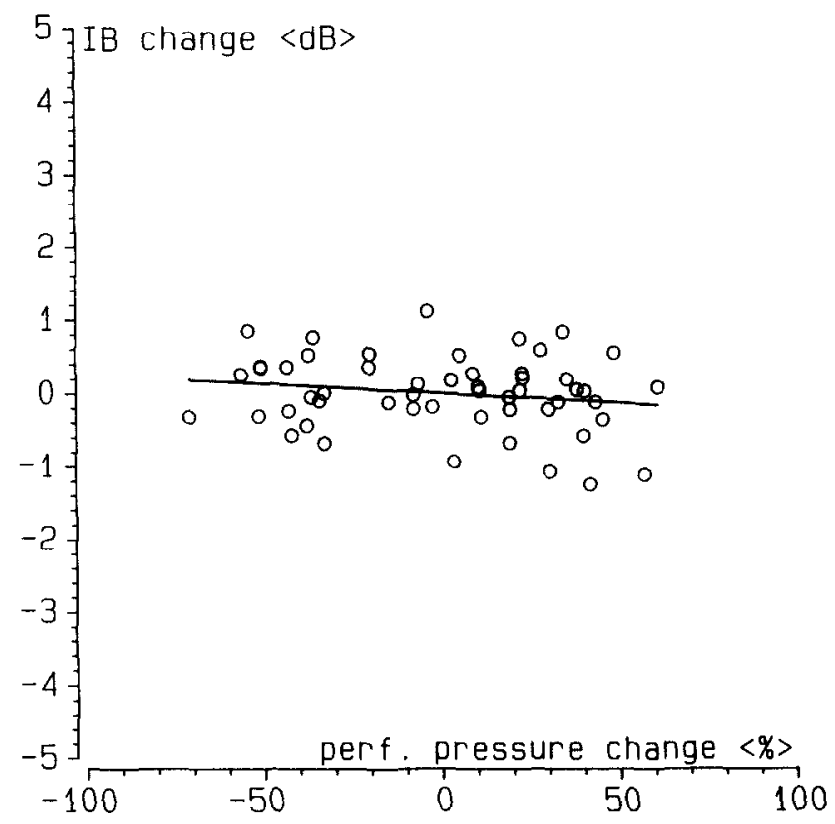

Fig. 4. The relationship of the changes in integrated backscatter (IB) versus the changes in perfusion pressure obtained during the experiments at constant balloon volume. 
It is generally thought that these isolated hearts have a lower contractility than in in vivo conditions (Suga et al. 1973). The observed $E_{\max }$ values, signifying a load-independent index of contractility, although slightly lower than $E_{\max }$ values measured in the open-chest dog, were similar to those of isolated dog and rabbit hearts after normalization to $100 \mathrm{~g}$ of cardiac tissue (Goto et al. 1988b; Nozawa et al. 1988; Suga et al. 1973)

In a previous study (Krams et al. 1994), we have shown that these isolated pig hearts remained stable (both mechanically and biochemically) up to $4 \mathrm{~h}$ of perfusion, a period exceeding this protocol.

A restriction of our protocol was the upper limitation of the left ventricular pressure to prevent the aortic valve from opening. Compared to normal, the isovolumic hearts were beating at lower left ventricular volumes and, therefore, the myocardial thickness is expected to be slightly higher. The contribution of this effect to the results was considered small since both variables, integrated backscatter and wall thickness, were normalized and expressed as a ratio.

Cyclic variation and end-systolic wall thickening during isovolumic contraction

An isolated heart with a fluid-filled balloon in the left ventricle generates global isovolumic cardiac contractions. This does not imply that regional wall thickness must be constant throughout the cardiac cycle. Due to geometrical changes of the heart during the cardiac cycle, regional myocardial wall thickness will increase or decrease depending on the specific region, but the spatial average over the left ventricular wall of these changes must be zero.

In the present study, the myocardial wall thickening and ultrasound integrated backscatter power were measured regionally at a fixed position of the left ventricular free wall. During the experiments with constant perfusion pressure, the range of wall-thickening changes appeared to be $\pm 4.5 \%$ effectively. This is small compared to the $40 \%$ wall thickening observed in pig hearts under normal conditions (Sassen et al. 1991).

The cyclic variation turned out to be almost zero $(0.19 \mathrm{~dB})$ with a relatively large residual variance $(1.5$ $\mathrm{dB}$ ). Due to this residual variance, there was no statistically significant relation between the end-systolic wall thickening and the magnitude of cyclic variation, at this state of reduced contractility.

This observation endorses the existence of an empirical inverse relationship between the cyclic variation of integrated backscatter and myocardial wall thickening (Rijsterborgh et al. 1991; Sagar et al. 1987; Wickline et al. 1985a,b). These studies, however, were performed in in vivo experiments and the influence of cyclic variation of acoustic impedance of myofibers due to tension could not be separated from wall thickness.

During isovolumic contraction, the left ventricular pressure reached normal physiological values, indicating that the myocardium was cycling through a normal range of its tension. We therefore have to reject the hypothesis that integrated backscatter is related to tension of the contractile elements in the myocardium.

The quasistatic assessment of the relationship between integrated backscatter and wall thickness

In a previous study (van der Steen et al. 1991) we investigated integrated backscatter and myocardial wall thickness in freshly excised nonperfused tissue. The purpose of that study was to extend the investigation of the effect of wall thickness on integrated backscatter to normal nonperfused myocardial tissue. $\Lambda$ strong inverse relationship was found.

The isovolumic model offers the unique opportunity to assess the relationship between integrated backscatter and wall thickness in a similar manner, while perfusion pressure is kept constant. With the increase of the balloon volume, the average myocardial wall thickness decreases (Fig. 2, top) and average integrated backscatter increases (Fig. 2, bottom), both significantly. In this setup the average of myocardial wall thickness over the cardiac cycle changed from $-15 \%$ to $+21 \%$, which is comparable to the range found in the normal beating heart. There is a significant inverse relationship between the changes of integrated backscatter and the changes of myocardial wall thickness. In the present study, an average slope of $-0.14 \pm$ $0.014 \mathrm{~dB}$ per percent wall thickening was observed (Fig. 3). This slope is comparable to that obtained in freshly excised nonperfused myocardial tissue in a similar quasistatic manner $(-0.12 \pm 0.072 \mathrm{~dB}$ per percent) (van der Steen et al. 1991).

In open-chest pigs with normal contractile behaviour, a lower slope was found with a higher variance $(-0.036 \pm 0.060 \mathrm{~dB}$ per percent) (Rijsterborgh et al. 1991 ). The latter relationship remained valid even during acute ischemic periods.

\section{The influence of the perfusion pressure on the measure- ments of integrated backscatter \\ The measurements of ultrasound myocardial inte- grated backscatter have anisotropic properties related to the orientation of the myofibers within the cardiac muscle (Hoffmeister et al. 1991; Maderas et al. 1988; Mottley and Miller 1988; Recchia et al. 1993, 1995; Wickline et al. 1991, 1992). From these investigations it can be concluded that the ultrasound backscatter from myocardial tissue is a result of the interaction between ultrasound and the myocytes or myofibers.}


The cyclic variation of the integrated backscatter during the cardiac cycle can be caused by a change in acoustic impedance of the myofibers or a change in their physical dimensions. This could explain the empirical wall thickness dependency of integrated backscatter, despite its residual variance.

However, observations in stunned dog myocardium (Mulinski et al. 1989a,b) are more difficult to explain by this simple model. If the myocardium is reperfused after a brief period of ischemia, normal cyclic variation of the integrated backscatter can be observed, despite a deficiency of myocardial wall thickening.

In a separate article, we investigated the integrated backscatter-wall thickness relationship in stunned myocardium in pigs (van der Steen et al. 1995). We found a reduction in cyclic variation of both integrated backscatter and wall thickness after occlusion and a simultaneous return of these characteristics after reperfusion. It is likely that the difference between our findings and those of Milunski et al. (1989a,b) can be explained by the difference in experimental model. The existence of collaterals in dog myocardium versus the absence of collaterals in pig myocardium might play a role.

These measurements indicate that there might be other factors which influence the levels of ultrasound backscatter. One of the possible factors that influence the levels of integrated backscatter could be the cyclic change of the intramyocardial vascular volume. In normally perfused myocardium, the size of the vessels will change as a result of extravascular compression during the cardiac cycle (Spaan 1991). This may be a determinant of the backscatter power from myocardial tissue and could explain the observations in stunned dog myocardium by Milunski et al. (1989a,b) .

To investigate the changes of the integrated backscatter measurements related to the changes of the intramyocardial vascular volume, independent of the wall thickness, measurements of cyclic backscatter at different coronary perfusion pressure were performed at the same balloon volume. However, since no independent measurement of the size of the intramyocardial vascular compartment is presently available, we assumed that the vascular volume changed with the different coronary perfusion pressures (Spaan 1991).

We observed a small, though statistically significant, drop of $1 \%$ in wall thickness when reperfusion was lowered from 120 to $80 \mathrm{mmHg}$. No significant change was found in integrated backscatter levels, which leads to the rejection of the hypothesis that the hackscatter level is related to the intravascular vessel volume in the perfusion pressure range investigated. This conclusion is in accordance with the studies performed by Haasler et al. (1993) and McPherson et al. (1986), who studied myocardial integrated backscatter and its cyclic variation in dogs under normal contraction after injection of adenosine to increase the blood flow.

\section{CONCLUSIONS}

In normally perfused myocardium, with a normal contractile state, but experimentally reduced wall thickening, there is no cyclic variation of the integrated backscatter. There is no significant contribution of changes in the intramyocardial vascular volume to the integrated backscatter level or to its cyclic variation. A quasistatic relationship between average myocardial wall thickness and average integrated backscatter level is maintained, even without a normal contractile pattern of the myocardial wall.

Acknowledgements - These investigations are supported by Grant RGN02332 from The Netherlands Technology Foundation (STW).

\section{REFERENCES}

Barzilai B, Ma'sr?: EI, Sobel BE, Miller JG, Perez JE. Effects of myocardial contraction on ultrasonic backscatter before and after ischemia. Am J Physiol 1984;247:H478-H483.

Bloomfield P. Fourier analysis of time series: an introduction. New York: Wiley; 1976:80-85.

Glueck RM, Mottley JG, Sobel BE, Miller JG, Pérez JE. Changes in ultrasonic attenuation and backscatter of muscle with state of contraction. Ultrasound Med Biol 1985;11:605-610

Goto Y, Slinker BK, LeWinter MM. Accuracy of volume measurement of rabbit left ventricle by balloon method. An J Pliysiol 1988a; 255:H394-H396.

Goto $Y$, Slinker BK, LeWinter MM. Similar normalized $E_{\max }$ and $\mathrm{O}_{2}$ consumption-pressure volume area relation in rabbit and $\mathrm{dog}$. Am J Phys 1988b;255 (Heart Circ Phys 24):H366-H374.

Haasler GB, Rhyne TL, Komorowski R, Boerboom LE. Sagar KB The lack of effect of hemodilution, myocardial water content, and increased coronary artery blood flow on integrated backscatter in the beating canine heart. Ultrason Imag 1993; 15:25-35.

Hoffmeister BK, Wong AK, Verdonck ED, Wickline SA, Miller JG. Anisotropy of ultrasonic backscatter from human tendon compared to that from normal human myocardium. IEEE Trans 1991: UFFC 91CH3079-1:1127-1131.

Krams R, Duncker DJ, McFalls EO, Verdouw PD. Elastic recoil a sensitive measure of loss of function during brief periods of ischemia and reperfusion. J Mol Cell Cardiol 1991;23(suppl 5) : $\mathrm{S} 23$.

Krams R, Janssen M, van der Lee C, van Meegen J, de Jong JW, et al. Loss of elastic recoil in postischemic myocardium induces rightward shift of the systolic pressure volume relationship. Am J Physiol 1994;267:H1 1557-H1564.

Lancée CT, Mastik F, Rijsterborgh H, Bom N. Myocardial backscatter analysis in animal experiments. Ultrasonics 1988;26:155163.

Maderas EI, Barzilai B, Pérez JE, Sobel BE, Miller JG. Changes in myocardial backscatter throughout the cardiac cycle. Ultrason Imag 1983:5:229-239.

Maderas EI, Pérez J, Sobel BE, Mottley JG, Miller JG. Anisotropy of the ultrasonic backscatter of myocardial tissue: II. Measurements in vitro. J Acoust Soc Am 1988;83:762-769.

McPherson DD, Skorton DJ, Wilbricht CJ, Fleagle SR. Haugen $\mathrm{JA}$, et al. Is myocardial perfusion a determinant of integrated ultrasound backscatter? Clin Res 1986;34:898A

Miller JG, Pérez JE, Mottley JG, Madaras EI, Johnston PH, et al. Myocardial tissue characterization: an approach based on quantitative backscattcr and attenuation. Proc IEEE Ultrason Symp 1983: CH1947-1:782-793. 
Milunski MR. Mohr GA, Pérez JE, Vered Z, Wear KA, et al. Ultrasonic tissue characterization with integrated backscatter: Acute myocardial ischemia, reperfusion, and stunned myocardium in patients. Circulation 1989a; $80: 491 \ldots 503$.

Milunski MR, Mohr GA, Wear KA, Sobel BE, Miller JG, et al, Early identification with ultrasonic integrated backscatter of viable but stunned myocardium in dogs. J Am Coll Cardiol 1989b;14:462471 .

Mimbs JW, Batwens D, Cohen RD, O'Donnell M, Miller JG, et al. Effects of myocardial ischemia on quantitative ultrasonic backscatter and identification of responsible determinants. Circ Res 1981:49:89-96.

Morse PM, Ingard KU. Theoretical acoustics. New York: McGrawHill, 1968:400-441.

Mottley JG, Glueck RM, Pérez JE, Sobel BE, Miller JG. Regional differences in the cyclic variation of myocardial backscatter that parallel regional differences in contractile performance. $J$ Acoust Soc Am 1984; 76:1617-1623.

Mottley JG, Miller JG. Anisotropy of the ultrasonic backscatter of myocardial tissue: $\mathbf{I}$. Theory and measurements in vitro. J Acoust Soc Am 1988;83:755-761.

Nozawa T, Yasumara Y, Futaki S, Tanaka N, Uenishi M, Suga $H$. Efficiency of energy transfer from pressure-volume area to external mechanical work increases with contractile state and decreases with afterload in the left ventricle of the anesthetized closed-chest dog. Circulation 1988;77:1116-1124.

Recchia D, Miller JG, Wickline SA. Quantification of ultrasonic anisotropy in normal myocardium with lateral gain compensation of two dimensional integrated backscatter images. Ultrasound Med Biol 1993: 19:497-505.

Recchia D, Hall CS, Shepard RK, Miller JG, Wickline SA. Mechanisms of the view dependence of ultrasonic backscatter from normal myocardium. IEEE Trans 1995; UFFC-42:91-98.

Rijsterborgh H, Mastik F, Lancée CT, van der Steen AFW, Sassen LMA, et al. Ultrasonic myocardial integrated backscatter and myocardial wall thickness in animal experiments. Ultrasound Med Biol 1990; 16:29-36.

Rijsterborgh H, Mastik F, Lancée CT, Sassen LMA, Verdouw PD, et al. The relative contributions of myocardial wall thickness and ischemia to ultrasonic myocardial integrated backscatter during experimental ischemia. Ultrasound Med Biol 1991;17:41-48.

Sagar KB, Rhyne TL, Warltier DC, Pelc LE, Wann LS. Intramyocar- dial variability in integrated backscatter: effects of coronary $00^{\circ}$ clusion and reperfusion. Circulation 1987;75:436-442

Sagar KB, Pelc LE, Rhyne TL, Wann LS, Warltier DC. Influence of heart rate, preload, afterload, and inotropic state on myocardial ultrasonic backscatter. Circulation 1988:77:478-483.

Sassen LMA, Bezstarosti K, van der Giessen WJ. Lamers JMJ, Verdouw PD. L.-Propionylcaniline increases postischemic blood flow but does not affect recovery of energy charge. Am J Physiol 1991:261 ( Heart Circ Physiol 30):172-180

Spaan JAE. Coronary blood flow. Developments in cardiovascular medicine ( vol 124). Dordrecht: Kluwer, 1991.

van der Steen AFW, Rijsterborgh H, Mastik F, Lancée CT, van Hoorn WM, et al. Influence of attenuation on measurements of ultrasonic myocardial integrated backscatter during the cardiac cycle. Ultrasound Med Biol 1991; 17:869-877.

van der Steen AFW, Rijsterborgh H, Krams R, Mastik F, Lancée CT, et al. Cyclic variation of integrated backscatter and wall thickness in stunned porcine myocardium. Ultrason Bull $1995 ; 23: 6-10$.

Stubbs J, Widdas WF. The interrelationship of weight change and coronary flow in the isolated perfused rabbit heart. J Physiol $1959 ; 148: 403-416$

Suga H, Sagawa K, Shoukas AA. Load independence of the instantaneous pressure-volume ratio of the canine left ventricle and effects of epinephrine and heart rate on the ratio. Circ Res $1973: 32: 314-320$.

Wear KA, Milunski MR, Wickline SA, Pérez JE, Sobel BE, et al. Contraction-related variation dependence of acoustic properties of canine myocardium. J Acoust Soc Am 1989;86:2067-2072.

Wear KA, Shoup TA, Popp RL. Ultrasonic characterization of canine myocardium contraction. IEEE Trans 1986:UFFC-33/ $4: 34 \%-353$.

Wickline SA, Thomas, LJ III, Miller JG, Sobel BE, Pérez JE. The dependence of myocardial ultrasonic integrated backscatter on contractile performance. Circulation 1985a;72:183-192.

Wickline SA, Thomas LJ III, Miller JG, Sobel BE, Pérez JE. A relationship between ultrasonic integrated backscatter and myocardial contractile function. J Clin Invest 1985b; 76:2151-2160.

Wickline SA, Verdonk ED, Miller JG. Three-dimensional characterization of human ventricular myofiber architecture by ultrasonic backscatter. J Clin Invest 1991;88:438-446.

Wickline SA, Verdonk ED, Wong AK, Shepard RK, Miller JG. Structural remodeling of human myocardial tissue after infarction: quantification with ultrasonic backscatter. Circulation 1992;85:259-268. 